ISSN: 2162-3104 Print/ ISSN: 2166-3750 Online

Volume 8, Issue 2 (2018), pp. 1198-1219

(C) Journal of International Students

http://jistudents.org/

doi: 10.5281/zenodo. 1250421

\title{
Striving for Success: Academic Adjustment of International Students in the U.S.
}

\author{
Gilberte Bastien \\ Morehouse School of Medicine, USA \\ Tanja Seifen-Adkins \\ University of Mississippi, USA \\ Laura R. Johnson \\ University of Mississippi, USA
}

\begin{abstract}
Few studies have provided an examination of the academic component of acculturation. This study sought to extend the work in this area by examining factors impacting academic adjustment of international students in the US and compare results to factors of psychological adjustment. Predictors of academic adjustment were investigated with a sample of 122 international students. Hierarchical regressions revealed length of stay in the U.S., English proficiency, and help-seeking predicted academic adjustment, whereas age and attachment to the university community predicted psychological adjustment. Psychological adjustment was associated with acculturation strategy and cultural distance. Results suggest the need for targeted support interventions to facilitate psychological and socio-cultural adjustment in each domain.
\end{abstract}

Keywords: academic adjustment, acculturation, international students, psychological adjustment 
Every year, millions of students enroll in post-secondary institutions across the United States and embark on one of the most challenging phases of adult development. For many students, the transition from high school to college involves a number of hurdles that can result in the experience of psychological distress. Increased academic demands, personal responsibilities (e.g., managing finances, prioritizing duties, etc.), and distance from family contribute to the difficulty of the adjustment process and can ultimately result in withdrawal from school, if not properly addressed (Gerdes \& Mallinkrodt, 1994). For international students, who are often uprooted from all that is familiar, adjusting to life as students in the U.S. poses an even greater challenge, making them particularly vulnerable to adverse psychological outcomes (Poyrazli, Arbona, Bullington, \& Pisecco, 2001; Zhang \& Dixon, 2003). According to a report released by the Institute of International Education (IIE) in 2015, nearly a million international students $(974,926)$ were enrolled in universities in the U.S. during the 2014-2015 academic year, indicating international students make up an estimated $4.8 \%$ of university students in the United States (Open Doors, 2015). International students contribute unique perspectives that serve to enrich the educational experience of all students who attend U.S. institutions of higher learning (Wolanin, 2000). In addition to their academic contributions, international students represent a foreign policy asset. International student enrollment contributes to the U.S. economy and impacts international relationships that are of key significance, given the increasingly global nature of business, politics, and the economy. In order to facilitate academic success and ensure continued enrollment of international students, university personnel must better understand and meet the needs of this unique and diverse population.

The adjustment of international students has been the focus of a growing body of empirical work. Much of the work in this area has been grounded in Berry's (1997) theory of acculturation. Building on this, Ward and Kennedy $(1993,1994)$ have offered a conceptualization of acculturation as comprised of two distinct components: psychological and socio-cultural adjustment. Few studies have connected Berry and Ward's models to inform their investigations of cultural adjustment. 


\section{LITERATURE REVIEW}

\section{Cultural Adjustment and Acculturative Stress}

Acculturation describes the process through which individuals learn to adapt to a new cultural situation. More specifically, Berry (1997) defines acculturation as changes in values, beliefs, and behaviors that occur as a result of sustained contact between two or more cultures. A major component of the acculturation process is acculturative stress, which encompasses mildly pathological and disruptive behaviors as well as symptoms of anxiety, depression, identity confusion, anger, substance abuse, and family conflict (Berry, Kim, Minde, \& Mok, 1987; Sandhu \& Asrabadi, 1998). The experience and management of acculturative stress is argued to vary depending on the strategy adopted in approaching cultural adjustment. In his acculturation model, Berry (1997) postulates four acculturation strategies: assimilation (describes a decision to establish a connection with the dominant culture while neglecting aspects of one's culture of origin), separation (decision to maintain a connection with one's native culture while rejecting the values and norms of the host culture), integration (decision to embrace the values, behaviors, and norms of both the heritage and host cultures), and marginalization (characterized by a rejection of both the heritage and host cultures, thereby isolating oneself). A number of studies in this area have provided support for these strategies as being differentially adaptive (Berry, 1998; Ryder, Alden, \& Paulhus, 2000; Sodowsky \& Plake, 1992; Barratt \& Huba, 1994; Ward \& Kennedy, 1994). Specifically, the marginalization mode or strategy of acculturation has been shown to be associated with higher acculturative stress and a number of adverse psychological outcomes, whereas integration/biculturalism is argued to be associated with lower levels of acculturative stress (Berry et al., 1987).

\section{Psychological vs. Socio-cultural Adjustment}

A related consideration of interest is a distinction between the psychological and socio-cultural components of cultural adjustment. The psychological aspect of acculturation describes an acculturating individual's sense of well-being and satisfaction, whereas socio-cultural adjustment refers to the social learning process through which the individual learns to navigate the new cultural environment. Compared to psychological adjustment, the social learning process is described as rather linear learning process, including for example language and performance success (Ward \& 
Searle, 1991; Ward \& Kennedy, 1993). Acculturation research has provided support for significant qualitative differences between these categories, suggesting they are influenced by different factors (Ward \& Kennedy, 1993; Spencer-Oatey \& Xiong, 2006; Johnson \& Sandhu, 2007). In their 1993 studies, Ward \& Kennedy concluded the best predictors of psychological adjustment were personality factors (e.g., locus of control, introversion/extraversion, etc.), life changes, and social support. On the other hand, socio-cultural adjustment was best predicted by factors such as amount of time spent in the host culture, cultural distance, English proficiency, acculturation strategy, and quantity of interactions with natives of the host culture (Ward \& Kennedy, 1993).

\section{Academic Adjustment of International Students}

Academic adjustment involves more than a students' potential to be academically successful. It encompasses factors such as motivation, achievement, institutional commitment (Gerdes \& Mallinkrodt, 1994), as well as taking action to meet academic demands, experiencing a sense of purpose, and overall satisfaction with the academic life (Baker \& Siryk, 1984a, 1984b) For international students, academic adjustment plays a key component in the overall adjustment process (Gerdes \& Mallinkrodt, 1994; Lin \& Yi, 1997; Mori, 2000; Poyrazli et al., 2001).

In addition to the stressors commonly faced by most acculturating groups, international students must deal with difficulties stemming from significant pedagogical differences (Mori, 2000). International students often receive their primary education from foreign institutions based on educational systems that differ significantly from U.S. institutions of higher learning. Common features of the U.S. pedagogy such as oral presentations, group projects, and class discussions may be unfamiliar to international students, posing a particular challenge (Cadieux \& Wehrly, 1986). International students may lack familiarity with the testing and/or grading system of the university (Lin \& Yi, 1997). In a more recent study that included qualitative data from the past decade, Gebhard (2012) found that international students often struggle with academic language problems. More specifically, students reported difficulties with academic reading (e.g. content difficulty), cultural norms in the classroom (e.g. speaking without raising hand), and understanding the teacher and taking notes during lectures and seminars. In addition to being confronted with frustration and anger due to language and communication barriers, international students may also 
feel alienated due to resentment from colleagues who may view them as lacking competency or qualifications for assistantship positions due to their lack of English proficiency (Lin \& Yi, 1997). Thus, international students often experience considerable obstacles in adjusting to U.S. academic norms (Pedersen, 1991; Sandhu \& Asrabadi, 1994). Given the unique challenges associated with navigating a new pedagogical system, it is not surprising that international students have been found to be particularly vulnerable to academic adjustment difficulties when compared to their mainstream counterparts (Gerdes \& Mallinkrodt, 1994; Lin \& Yi, 1997; Mori, 2000; Poyrazli et al., 2001).

\section{Variables Influencing Academic Adjustment}

Cultural distance describes the extent to which two or more cultures differ from one another in areas such as clothing, cuisine, social conventions, religion, weather, wealth, and education (Babiker, Cox, \& Miller, 1980). Studies investigating the direct impact of cultural distance on academic adjustment are rare. However, in one study, greater cultural distance predicted more adjustment difficulties (Poyrazli et al., 2001). In further support of this link, studies in this area have indicated pedagogical differences tend to be particularly problematic for students from Asia, the Middle East, and Africa, areas that have been noted as having a greater cultural distance in relation to the U.S., when compared to those from Westernized cultures (Aubrey, 1991).

Social support has been widely studied and consistently linked to overall psychological well-being. Past research has provided support for a moderating role of social support with regards to psychological distress stemming from the acculturation process (Yeh \& Inose, 2003; Misra, Crist, $\&$ Burant, 2003). Yeh and Inose (2003) found that social support satisfaction and social connectedness were significant predictors of acculturative stress. As it relates to academic adjustment specifically, previous research has provided preliminary support for the vital role of social support in the academic adjustment of international students. The results of a study conducted by Mallinckrodt \& Leong (1992) indicated social support (particularly from one's academic program) is associated with better academic outcomes and psychological well-being.

English proficiency is another key variable that has been found to greatly influence adjustment of international students (Olivas \& Li, 2006; Mori, 2000; Zhang \& Dixon, 2003; Poyrazli et al., 2001). Using an 
ethnically mixed sample of international students, Olivas and Li (2006) found a strong correlation between language proficiency and adjustment. The authors concluded low English proficiency affects adjustment by reducing the likelihood of seeking social interactions, which in turn, reduces access to useful information that might facilitate adjustment (Olivas \& $\mathrm{Li}$, 2006). International students are more likely to have difficulty understanding lectures, understanding class readings, and articulating their knowledge in presentations and/or essays (Lin \& Yi, 1997; Gebhard, 2012). Finally, help seeking describes efforts to increase mastery and competence by seeking assistance to facilitate completion of relevant tasks (Nadler, 1986; Nadler, 1987; Zhang \& Dixon, 2003). With regard to academic functioning, help seeking behaviors would include attempts to secure aid with the ultimate aim of improving academic performance and achievement. Examples may include receiving tutoring, making use of faculty office hours, participating in study groups, use of academic support services provided through the university, etc.

\section{Current Study}

As illustrated by the above review of acculturation research to date, the adjustment of international students is greatly influenced by a number of factors. Specifically, previous work in this area has pointed to a significant role of acculturation strategy, acculturative stress, social support, cultural distance, as well as English proficiency. However, these studies have often focused on the psychological aspect of acculturation, while largely neglecting the socio-cultural component of cultural adjustment. For the purpose of this study, academic adjustment is conceptualized as representing the socio-cultural learning process of adjustment. International students have to learn and understand the social and cultural norms of a new environment in order to successfully navigate a foreign academic context. Outcomes of this socio-cultural learning may include knowledge and understanding of behavioral norms, language competency, and the ability to succeed in the classroom environment. Therefore, measures of academic adjustment and GPA were chosen to measure socio-cultural learning. GPA was included to account for academic success, which is an important component of academic adjustment. Conversely, measures of acculturative stress and emotional adjustment were selected to represent the psychological component of cultural adjustment. 
The present study sought to reaffirm the above variables as predictors by examining the extent to which their previously illustrated effects extend to the socio-cultural component of adjustment, more specifically academic adjustment within a sample of international students. Additionally, the role of active coping (in the form of academic help seeking behaviors) was investigated. Although past research has provided considerable support for the integration/ bicultural modes of acculturation as most adaptive and the marginalization/assimilation modes as least adaptive, these studies have largely focused on the psychological aspect of cultural adjustment, while failing to examine the influence of acculturation strategy on socio-cultural adjustment. Thus, the final aim of this study was to investigate the differential impact of acculturation strategy on psychological and socio-cultural adjustment.

\section{Hypotheses}

Overall, this study was driven by two primary questions: (1) What is the nature of the adjustment process experienced by international students and (2) Are psychological and academic adjustment predicted by the same factors? Specifically, the present study investigated the following hypotheses: (a) demographic factors (age and length of time spent in the U.S.), pre-acculturation factors (cultural distance and English proficiency), and potential moderating factors (social support, academic help-seeking, and acculturation strategy) will predict acculturative stress and personalemotional adjustment; (b) demographic factors, pre-acculturation factors, and potential moderating factors will predict academic adjustment and GPA.

\section{RESEARCH METHOD}

\section{Participants}

The sample for the study consisted of 122 students at a university in the Southern US. Participants were recruited with the assistance of the International Programs Office as well as a number of international student organizations. There were 69 female and 53 male participants ranging in age from 17 to $40(\mathrm{M}=23.57, \mathrm{SD}=4.83)$. The majority of participants were single $(93 \%)$, undergraduate students $(62 \%)$. Regarding region of origin, $50 \%$ of the participants were from Asia, $23 \%$ from Africa, 16\% from Europe, 7\% from South America, and 4\% from North America. 


\section{Measures}

\section{Socio-Demographic Questionnaire}

Developed by the researcher, the questionnaire covered basic demographic variables (e.g., age, gender, current GPA), exposure to American culture (e.g., country of origin, level of English proficiency), social life (e.g., involvement in extracurricular activities/organizations, number of American friends), as well as questions about academic helpseeking (e.g., use of faculty office hours, use of free tutoring etc.). Adopting the methods used by Barrat and Huba (1994), level of English proficiency was assessed using the following questions: 'What is your present level of English fluency?', 'How comfortable are you communicating in English?', and 'How often do you communicate in English?'. Participants answered these questions using a 5-point Likert type scale. Previous studies have reported Cronbach's alphas ranging from .56 to .78 for the 3 items (Barrat \& Huba, 1994; Cross, 1995; Yeh \& Inose, 2003).

\section{Acculturative Stress Scale for International Students (ASSIS)}

This measure was developed by Sandhu and Asrabadi (1994) and was used to assess the adjustment problems of international students. The ASSIS consists of 36 items using a 7-point Likert type response format. The ASSIS is broken down into 7 subscales: Perceived discrimination, homesickness, perceived hate, fear, stress due to change, guilt, and miscellaneous. Sandhu and Asrabadi (1998) reported that the scale showed strong internal consistency and split-half reliability. Studies examining the psychometric properties of the ASSIS have reported internal consistency of .92 or above (Constantine, Okazaki, \& Utsey, 2004; Duru \& Poyrazli, 2007; Poyrazli et al., 2004; Yeh \& Inose 2003).

\section{Vancouver Index of Acculturation (VIA) (Ryder, Alden, \& Paulhus, 2000).}

This measure of acculturation was used to assess participants' acculturation to and identification with both their culture of origin and the host culture (i.e., U.S. American culture). The VIA is comprised of 20 items rated on a 9-point Likert-type scale. Half of the items assess identification with the culture of origin (Heritage Scale), while the remaining 10 items measure identification with the new culture (Host Scale). Previous studies that have investigated the psychometric properties of this measure have 
provided promising evidence for its effective use with a variety of ethnocultural populations. For the Heritage scale, Ryder and colleagues (2000) reported Cronbach's alpha coefficients of .91, .92, and .91 for Chinese, East Asian, and miscellaneous samples, respectively. The Host subscale also yielded high Cronbach's alpha coefficients and mean interitem correlations for the three samples $(.89, .85$, and .87$)$.

\section{Student Adaptation to College Questionnaire (SACQ; Baker \& Siryk, 1989)}

The SACQ is a 67-item self-report questionnaire originally developed for publication in 1989 (Baker \& Siryk, 1999). The SACQ was revised in 1999 and measures four aspects of college adjustment: Academic, Social, Personal-Emotional, and Attachment to the University. Regarding the psychometric properties of the SACQ, internal reliability coefficients for the full scale range from .81 to .90 . Alpha coefficients for the individual scales range from .81 to .90 for Academic adjustment subscale, .83 to .91 for the Social adjustment subscale, .77 to .86 for the Emotional adjustment subscale, and .85 to .91 for the Attachment subscale. Additionally, Baker and Siryk $(1989,1999)$ described a number of studies providing evidence for criterion-related or construct validity for each of the four subscales of the SACQ. Specifically, the SACQ subscales have been found to correlate with variables such as student attrition, grade point average, use of campus counseling or psychological services, as well as social activity involvement (Baker \& Siryk, 1999).

\section{Social Support}

Social support was measured using a modified version of a social support measure created by Koeske and Koeske $(1989,1993)$. This measure has been used in previous studies using international student samples (e.g., Lee et al., 2004). For the current study, participants were asked to rate the amount of support they receive from (1) international student friends from countries other than their own, (2) co-national international student friends, (3) non-student international university and community members not from their home country, (4) non-student international co-nationals affiliated with the university or community, (5) American university students, (6) American non-student members of the university or greater community, and (7) family members. The total score provided by this scale was used in the present study as a measure of overall social support. The sample for this 
study yielded a Cronbach's alpha of .83 for this measure, suggesting high internal reliability.

\section{Procedure}

\section{Recruitment}

Participants were recruited as part of a larger study designed to gather information from the local international student population. Approaches for recruitment consisted of emails, posted fliers, and in-person solicitation through international organizations on campus as well as a weekly international student café. The university's International Programs Office (IPO) assisted in the recruitment of participants by providing access to the university's international student database. Students were sent a descriptive letter of the study via email and advertisements were placed in the weekly international student newsletter.

\section{Data Collection}

Participant packets were numbered and did not include participants' names to secure confidentiality and maintain anonymity. Surveys were distributed during scheduled appointments. Participants received a cover letter describing the purpose of the study as well as policies surrounding confidentiality. Self-report questionnaire packets consisting of a statement of IRB approval, a consent form, a demographic questionnaire, as well as the measures described above were then distributed to each participant. To control for order effects, the measures were arranged in a counterbalanced order. After completion, participants received a debriefing, and informative literature and campus resource pamphlets for international students were distributed.

\section{Data Analysis}

Data were screened for outliers, prior to analysis. Descriptive statistics were then calculated for each measure. Correlational analyses were conducted to explore bivariate relationships among the variables of interest and to determine which variables would be entered into the regression model. Hierarchical multiple regression analyses were then conducted to test the proposed hypotheses. 


\section{RESULTS}

\section{Descriptive Analyses}

Means and standard deviations were calculated for demographic variables such as age, GPA, and time in US, as well as each measure given (see Table 1). Internal consistency was checked and adequate results were found for each measure.

Table 1. Descriptive Statistics for Key Variables

\begin{tabular}{lccc} 
Variable/ Scale & Mean & \multicolumn{1}{l}{ SD } & Range \\
\hline Age in Years & 24 & 4.83 & $17-40$ \\
GPA & 3.60 & .44 & $2.00-4.00$ \\
Time in US (months) & 24 & 31.86 & $1-126$ \\
ASSIS & 78.72 & 21.88 & $40-134$ \\
VIA & & & \\
$\quad$ Heritage Subscale & 71.67 & 9.98 & $46-90$ \\
$\quad$ Host Subscale & 63.06 & 10.97 & $33-86$ \\
Social Support & & & \\
$\quad$ Emotional Support & 3.66 & .74 & $1.50-5.00$ \\
$\quad$ Practical Support & 3.64 & .77 & $1.43-5.00$ \\
$\quad$ Total & 44.07 & 11.17 & $13-70$ \\
SACQ & & & \\
$\quad$ Academic Adjustment & 106.15 & 16.88 & $66-152$ \\
Social Adjustment & 87.77 & 16.31 & $42-142$ \\
$\quad$ Personal-Emotional Adjustment & 82.75 & 16.90 & $43-119$ \\
$\quad$ Attachment to University & 37.71 & 6.86 & $19-55$ \\
Full Scale Score & 317.14 & 35.94 & $201-413$ \\
\hline
\end{tabular}

Note. Higher SACQ scores indicate better adjustment.

\section{Correlational Analyses}

In order to assess the degree of association among the four outcome variables, correlations were computed using Pearson's product moment correlations. Acculturative stress was significantly negatively correlated with emotional adjustment $(\mathrm{r}=-.407, \mathrm{p}<.01)$, suggesting the more acculturative stress experienced, the less well-adjusted international students will be emotionally. On the other hand, the data failed to demonstrate the expected significant correlation between academic adjustment and GPA, the 
variables selected to represent the socio-cultural domain of overall adjustment.

Overall social support was significantly correlated with connection to culture of origin $(\mathrm{r}=.214, \mathrm{p}<.05)$, but not with acculturative stress, nor academic adjustment. English proficiency was found to be significantly correlated with time spent in the U.S. $(r=.306, p<.01)$, and acculturation strategy, with a correlation of $r=.270$ for connection to the culture of origin $(\mathrm{p}<.01)$ and $\mathrm{r}=.289$ for connection to U.S. American culture $(\mathrm{p}<.01)$. Although English proficiency was not significantly related to overall social support, it was significantly related to practical social support $(r=.193, p<$ $.05)$, suggesting international students with greater proficiency in English are more likely to report greater availability of practical support. Connection to U.S. American culture was strongly positively correlated to time spent in the U.S. $(\mathrm{r}=.252, \mathrm{p}<.01)$, negatively related to social adjustment $(\mathrm{r}=$ $.205, \mathrm{p}<.05)$, and negatively related to acculturative stress $(\mathrm{r}=-.249, \mathrm{p}<$ $.01)$. Emotional adjustment was significantly related to age $(r=.214, \mathrm{p}<$ $.05)$ and attachment to the university community $(\mathrm{r}=.280, \mathrm{p}<.01)$. Significant relationships emerged between help-seeking behaviors and academic adjustment $(\mathrm{r}=.281, \mathrm{p}<.01)$, social adjustment $(\mathrm{r}=.334, \mathrm{p}<$ $.01)$, social support $(\mathrm{r}=-.211, \mathrm{p}<.05)$, as well as time spent in the U.S. $(\mathrm{r}=$ $-.300, \mathrm{p}<.01)$. However, the expected correlation between help-seeking and acculturative stress was not found. Finally, a significant inverse relationship was identified between attachment to the university community and acculturative stress $(\mathrm{r}=-.234, \mathrm{p}<.01)$.

An analysis of variance (ANOVA) was used to assess the association between participants' region of origin and the variables of interest. Region of origin was significantly associated with acculturative stress $(\mathrm{F}(4,117)=3.68, \mathrm{p}<.01)$ and English proficiency $(\mathrm{F}(4,117)=25.34$, $\mathrm{p}<.01)$. In order to further examine the significant relationships, post-hoc comparisons were computed using Tukey HSD test. Results revealed that participants from Europe reported significantly less acculturative stress as compared to participants from both Africa and Asia. Regarding English proficiency, significant differences were found between the scores of participants from Africa as compared to each other region (i.e., Asia, Europe, South America, etc.). Specifically, participants from European countries reported higher levels of proficiency as compared to participants from other regions. The expected significant association between place of origin and academic adjustment was not found $(\mathrm{F}(4,117)=1.86, \mathrm{p}=.121)$. 


\section{Regression Analyses}

Separate hierarchical multiple regressions were computed in order to assess the extent to which variables predict psychological (i.e. acculturative stress and emotional adjustment) and socio-cultural adjustment (i.e., GPA and academic adjustment). To test the predictive model proposed for psychological adjustment, two separate multiple regressions were performed, one for each outcome variable (acculturative stress and emotional adjustment). Predictor variables were entered into the model as follows: (1) Demographic factors (age and length of time spent in U.S.), (2) Pre-acculturation factors (English proficiency), and (3) Potential moderating factors (social support, academic help-seeking behaviors, and acculturation strategy).

Specific directional predictions about the role of individual factors were then assessed through an examination of beta weights. For acculturative stress, only the first model was significant and accounted for $5 \%$ of variance $(\mathrm{F}=3.21, \mathrm{p}<.05, \mathrm{R} 2=.05)$, with age being the only significant independent variable $(\beta=.24, \mathrm{p}<.05)$. Results for personalemotional adjustment were similar. Only the first model was significant and accounted for $5 \%$ of the variance $(\mathrm{F}=3.21, \mathrm{p}<.05, \mathrm{R} 2=.05)$, with age being the only significant variable in the model $(\beta=.24, \mathrm{p}<.05)$.

To test the hypothesis that age, time spent in the U.S., cultural distance, English proficiency, social support, acculturation strategy, and help-seeking behaviors predict socio-cultural adjustment, a multiple regression analysis was conducted with academic adjustment as the criterion variable. Because the correlation analyses failed to demonstrate a significant relationship between GPA and academic adjustment or between GPA and any of the predictor variables, GPA was eliminated as an outcome variable. The overall model predicting academic adjustment was significant $(\mathrm{F}=$ $4.751, \mathrm{p}<.001)$, and accounted for $24 \%$ of the variance $(\mathrm{R} 2=.237)$. Examination of the individual variables showed that time spent in the U.S. $(\beta=.38, \mathrm{p}<.001)$, English proficiency $(\beta=-.24, \mathrm{p}<.05)$, and help-seeking behaviors $(\beta=.42, \mathrm{p}<.001)$ contributed significantly to this effect.

\section{Supplemental Analyses}

Although it was not originally proposed as a predictor variable, information was gathered about participants' sense of attachment or connection to the university community. Correlation analyses indicated university attachment was significantly correlated with emotional 
adjustment $(\mathrm{r}=.280, \mathrm{p}<.01)$ and emotional social support $(\mathrm{r}=.199, \mathrm{p}<$ $.05)$. Based on the significant correlations among variables related to psychological adjustment, a separate regression, which included university attachment, was computed, with emotional adjustment as the outcome variable. Time spent in the U.S. was entered in the first step, followed by age and English proficiency. University attachment was added in the third step of the regression. This model was significant $(F=4.046, p<.01)$, and predicted $12 \%$ of the variance in emotional adjustment. University attachment $(\beta=.66, p<.05)$ contributed the most to the significance of the overall model.

The VIA was used to measure the construct of acculturation strategy. Mean scores on the heritage and host subscales suggest this sample had a more integrated or bicultural orientation overall. These data are comparable to those obtained in other studies (e.g. Swagler \& Jome, 2005). Attempts to group participants according to Berry's acculturation strategies proved to be a challenge, because there was insufficient variability in acculturation strategy for useful comparisons to be made. For exploratory purposes, a median split was performed to break the sample into groups based on high/low connection with the heritage and host cultures. The median for the heritage subscale was 71 and the median for the mainstream subscale was 65. Participants above the medians were classified as higher on the subscale and participants at or below the medians were classified as lower. Participants were then categorized into one of the four groups describing acculturation strategy. This acculturation variable was significantly associated with English proficiency $(\mathrm{F}(3,121)=4.32, \mathrm{p}<.01)$. Post-hoc comparisons using the Tukey HSD test indicated English proficiency scores of those placed in the Integrated category were significantly higher than those in the Marginalized category. It is worth emphasizing here that the acculturation strategy groupings are relative to the current sample, and analyses involving this variable should be interpreted with caution.

\section{DISCUSSION}

The present study investigated the adjustment experience of international students. The extent to which age, time spent in the U.S., cultural distance, English proficiency, social support, acculturation strategy, and help-seeking behaviors predict academic and psychological adjustment was explored. The 
collected data lend partial support for the hypotheses outlined at the outset of this project. Academic and emotional adjustment were predicted by different variables. Specifically, amount of time spent in the U.S., English proficiency, and help-seeking behaviors emerged as the strongest predictors of academic adjustment for international students, whereas age was the only significant predictor of psychological adjustment. Additional exploratory analyses revealed that level of attachment to the university community was also significantly associated with psychological adjustment but not academic adjustment. These findings are consistent with the literature suggesting psychological and socio-cultural adjustment are distinct components of overall adjustment (Ward \& Kennedy, 1993).

Our hypotheses regarding the relationships among the acculturation variables were not all supported. On the one hand, academic adjustment was significantly correlated with help-seeking behaviors. However, the data failed to demonstrate the expected significant association between academic adjustment and the following variables: cultural distance, social support, and acculturation strategy (as measured by connection to home and host culture, separately). The use of region of origin as a proxy of cultural distance rather than a standardized measure to assess this construct may have contributed to the nonsignificant association between cultural distance and academic adjustment. Although social support has consistently been linked to adjustment experience of international populations (Barratt \& Huba, 1994; Crockett et al., 2007; Gerdes \& Mallinkrodt, 1994; Lee, Koeske, \& Sales, 2004; Mallinckrodt \& Leong, 1992; Misra, Crist, \& Burant, 2003; Yeh, \& Inose, 2003), no such link was found in the present study. The measure of social support used in this study appears to have been difficult for the participants to understand. The social support measure was found to have an estimated reading grade level of 12.9 , but only $53 \%$ of the sample provided a response for every item, which suggests that comprehension likely could have been a problem. The lack of a clear association between academic adjustment and acculturation strategy may be attributed to the lack of sufficient variability in acculturation orientation within the sample. The majority of participants in this study endorsed an integrated or bicultural acculturation strategy, which made comparisons across different acculturation categories difficult.

Regarding psychological adjustment, age, connection to U.S. American culture, and university attachment were all found to be significantly related to acculturative stress and/or emotional adjustment. 
ANOVA analyses also revealed a significant association between acculturative stress and cultural distance, such that participants from regions argued to be more culturally similar to the U.S. endorsed less acculturative stress as compared to those from more culturally distant areas. However, no significant relationships were found between the psychological adjustment variables and English proficiency, social support, or connection to the participants' culture of origin. The lack of a significant association between psychological adjustment and English proficiency is consistent with findings from past studies suggesting English proficiency has a greater impact on the socio-cultural domain of adjustment (Ward \& Kennedy, 1993). The lack of a significant association between psychological adjustment and social support may also reflect the previously mentioned issue of comprehension of the social support measure.

\section{Limitations}

Regarding methodological limitations, the current study used a relatively small sample and lacked randomization. Additionally, all of the measures used were self-report, which means that social desirability may have impacted participants' responses to some extent. Further, the sample of international students used in this study represents a particular university in the Southern U.S. Thus, findings may not reflect the experience of international students at other colleges and universities in the U.S. and abroad. Additionally, as participants were not randomly selected, the sample may not fully represent the international student population at this university. The use of non-translated, English measures likely excluded less acculturated students or those who do not feel as confident in their knowledge of English. Additionally, the fact that the average GPA for this sample was 3.60 suggests the students who are having a difficult time academically either did not choose to participate or may have left and therefore could not be examined.

The sample of this study was not evenly balanced in terms of region of origin, with Asian students making up $50 \%$ of the sample. A related issue concerns the grouping of cultural distance based on continent of origin. As participants came from over 75 different countries, this approach fails to capture diversity within each category of origin. However, given the number of different countries, the uneven spread of participants across those countries, and the relatively small sample in this study, grouping based on continent seemed to make the most sense. This method of examining 
cultural distance based on region of origin has also been used in a number of other studies using international samples (Babiker, Cox, \& Miller, 1980; Constantine et al., 2005; Poyrazli, Kavanaugh, Baker, \& Al-Timimi, 2004; Sodowsky \& Plake, 1992; Spencer-Oatey \& Xiong, 2006; Yeh \& Inose 2003). Another limitation is the fact that the predictive model proposed in this study is nonexhaustive and accounts for a relatively small amount of variance. Other potentially significant predictors may include personality characteristics (e.g., introversion/extraversion) and experiences of discrimination. The exclusive use of quantitative methods (particularly selfreport measures) in this study may also represent a limitation. Qualitative methods likely would have provided further details to enhance understanding of the adjustment experience of international students. Despite these limitations, this study provided useful information that can deepen our understanding of the adjustment experience of international students.

\section{Future Directions}

Regarding future directions, mixed methods should be employed as often as possible when studying this population. The combination of qualitative and quantitative methods is likely to better elucidate the nuances of the phenomenon of acculturation. For example, use of qualitative methods may provide more information about the experiences of international students from specific countries, thereby facilitating a deeper understanding of cultural diversity within the regions examined in the present study. As previously mentioned, the proposed models in this study did not account for all of the variance in academic adjustment. As such, the role of many other potential predictors remains to be illustrated.

\section{CONCLUSION AND IMPLICATIONS}

Overall, results revealed differences between academic and psychological adjustment, which has important implications for working with international students in a university setting. Specifically, findings suggest the need for targeted interventions designed to meet both the psychological and sociocultural needs of the international student population. This study adds to the literature on acculturation and may be useful in the development of programs to foster positive adjustment experiences for international students. 
Results provide support for the influence of English proficiency and academic help-seeking on the academic adjustment of international students. A critical implication of these findings is that efforts to assist international students in doing their best academically should encourage and provide resources geared towards active help-seeking (e.g., use of writing center, career services, tutors, professor office hours, etc.). It is also critical that international students have ample opportunities to practice English in a "safe" environment (e.g., international conversation groups, host family programs, programs that pair international students with an American buddy).

Regarding psychological adjustment, it is imperative that university programs and/or workshops be available to assist international students in establishing a sense of connection to the greater university community. These efforts may be particularly crucial for students from culturally distant regions (e.g., Asia, Africa, Middle East, etc.). Previous research focused on international student adjustment also suggests a need to educate the university community in order to create a more welcoming environment for international students (Johnson \& Sandhu, 2007; Misra, Crist, \& Burant, 2003). Specifically, cultural awareness and sensitivity training for faculty and staff may facilitate greater understanding of the unique needs of international students.

\section{REFERENCES}

American Psychological Association. (2003). Guidelines on multicultural education, training, research, practice, and organizational change for psychologists. American Psychologist, 58, 377-402.

Aubrey, R. (1991). International students on campus: A challenge for counselors, medical providers, and clinicians. Smith College Studies in Social Work, 62(1), 20-33.

Babiker, I. E., Cox, J. L., \& Miller, P. M. (1980). The measurement of cultural distance and its relationship to medical consultations, symptomatology and examination performance of overseas students at Edinburgh University. Social Psychiatry and Psychiatric Epidemiology, 15, 109-116.

Baker, R. W., \& Siryk, B. (1984a). Measuring adjustment to college. Journal of counseling psychology, 31(2), 179.

Baker, R. W., \& Siryk, B. (1984b). Measuring academic motivation of matriculatingcollege freshmen. Journal of College Student Personnel.

Baker, R. W., \& Siryk, B. (1989). Student Adaptation to College Questionnaire. Los Angeles: Western Psychological Services. 
Baker, R., \& Siryk, B. (1999). The SACQ student adaptation to college questionnaire manual. Los Angeles: Western Psychological Services.

Barratt, M. F., \& Huba, M. E. (1994). Factors related to international undergraduate student adjustment in an American community. College Student Journal, 28(4), 422-436.

Berry, J. W. (1997). Immigration, acculturation, and adaptation. Applied Psychology: An International Review, 46, 5-34.

Berry, J. W. (1998). Acculturation and health: Theory and research. In S. S. Kazarian \& D. R. Evans (Eds.), Cultural clinical psychology: Theory, research, and practice (pp. 39-57). New York: Oxford University Press.

Berry, J. W., Kim, U., Minde, T., \& Mok, D. (1987). Comparative studies of acculturative stress. International Migration Review, 21, 490-511.

Cadieux, R. A., \& Wehrly, B. (1986). Advising and counseling the international student. New Directions for Student Services, 36, 51-63.

Constantine, M. G., Anderson, G. M., Berkel, L. A., Caldwell, L. D., \& Utsey, S. O. (2005). Examining the cultural adjustment experiences of African international college students: A qualitative analysis. Journal of Counseling Psychology, 52(1), 57-66.

Constantine, M. G., Okazaki, S., \& Utsey, S. O. (2004). Self-concealment, social self-efficacy, acculturative stress, and depression in African, Asian, and Latin American international college students. American Journal of Orthopsychiatry, 74, 230-241.

Crockett, L. J., Iturbide, M. I., Torres Stone, R. A., McGinley, M., Raffaelli, M., \& Carlo, G. (2007). Acculturative stress, social support, and coping: Relations to psychological adjustment among Mexican American college students. Cultural Diversity and Ethnic Minority Psychology, 13(4), 347355.

Cross, S. E. (1995). Self-construals, coping, and stress in cross-cultural adaptation. Journal of Cross-Cultural Psychology, 26, 673-697.

Duru, E., \& Poyrazli, S. (2007). Personality dimensions, psychosocial-demographic variables, and English language competency in predicting level of acculturative stress among Turkish international students. International Journal of Stress Management, 14, 99-110.

Gebhard, J.G. (2012). International Students' Adjustment Problems and Behaviors. Journal of International Students, 2, 184-193.

Gerdes, H., \& Mallinkrodt, B. (1994). Emotional, social, and academic adjustment of college students: A longitudinal study of retention. Journal of Counseling \& Development, 72(3) 281-288.

Johnson, L. R., \& Sandhu, D. S. (2007). Isolation, adjustment, and acculturation issues of international students: Intervention strategies for counselors. In H. D. Singaravelu \& M. Pope (Eds.), A handbook for counseling 
international students in the United States (pp.13-35). Alexandria, VA: American Counseling Association.

Koeske, G. F., \& Koeske, R. D. (1989). Work load and burnout: Can social support and perceived accomplishment help? Social Work, 34, 243-248.

Koeske, G. F., \& Koeske, R. D. (1993). A preliminary test of a stress-strainoutcome model for reconceptualizing the burnout phenomenon. Journal of Social Service Research, 17, 107-135.

Lee, J.-S., Koeske, G. F., \& Sales, E. (2004). Social support buffering of acculturative stress: A study of mental health symptoms among Korean international students. International Journal of Intercultural Relations, 28, 399-414.

Lin, J. G., \& Yi, J. K. (1997). Asian international students' adjustment: Issues and program suggestions. College Student Journal, 31(4), 473-479.

Mallinckrodt, B., \& Leong, F. T. (1992). International graduate students, stress, and social support. Journal of College Student Development, 33(1), 71-78.

Misra, R., Crist, M., \& Burant, C. J. (2003). Relationships among life stress, socialsupport, academic stressors, and reactions to stressors of internationalstudents in the United States. International Journal of Stress Management, 10(2), 137-157.

Mori, S. C. (2000). Addressing the mental health concerns of international students. Journal of Counseling \& Development, 78, 137-144.

Nadler, A. (1986). Help seeking as a cultural phenomenon: Differences between city and kibbutz dwellers. Journal of Personality and Social Psychology, 51(5), 976-982.

Nadler, A. (1987). Determinants of help seeking behaviour: The effects of helper's similarity, task centrality and recipient's self esteem. European Journal of Social Psychology, 17(1), 57-67.

Olivas, M., \& Li, C. (2006). Understanding stressors of international students in higher education: What college counselors and personnel need to know. Journal of Instructional Psychology, 33(3), 217-212.

Open Doors 2015 Fast Facts. International students in the U.S. (2015). Institute of International Education, 2015. Available from Open Doors Web site, http://opendoors.iienetwork.org

Pedersen, P. B. (1991). Counseling international students. Counseling Psychologist, 19(1), 10-58.

Poyrazli, S., Arbona, C., Bullington, R., \& Pisecco, S. (2001). Adjustment issues of Turkish college students studying in the United States. College Student Journal, 35(1), 52-62.

Poyrazli, S., Kavanaugh, P. R., Baker, A., \& Al-Timimi, N. (2004). Social support and demographic correlates of acculturative stress in international students. Journal of College Counseling, 7, 73-82. 
Ryder, A. G., Alden, L. E., \& Paulhus, D. L. (2000). Is acculturation unidimensional or bidimensional? A head-to-head comparison in the prediction of personality, self-identity, and adjustment. Journal of Personality and Social Psychology, 79, 49-65.

Sandhu, D.S., \& Asrabadi, B.R. (1994) Development of an acculturative stress scale for international students: Primary findings. Psychological Reports, 75, 435-448.

Sandhu, D. S., \& Asrabadi, B. R. (1998). An acculturative stress scale for international students: A practical approach to stress measurement. In C. P. Zalaquett \& R. J. Wood (Eds.), Evaluating Stress: A book of resources, Vol. 2 (pp. 1-33). Lanam, MD: Scarecrow Press.

Sodowsky, G. R., \& Plake, B. S. (1992). A study of acculturation differences among international people and suggestions for sensitivity to within-group differences. Journal of Counseling and Development, 71, 53-59.

Spencer-Oatey, H., \& Xiong, Z. (2006). Chinese students' psychological and sociocultural adjustments to Britain: An empirical study. Language, Culture, and Curriculum, 19, 37-53.

Swagler, M. A., \& Jome, L. M. (2005). The effects of personality and acculturation on the adjustment of North American sojourners in Taiwan. Journal of Counseling Psychology, 52, 527-536.

Ward, C., \& Kennedy, A. (1994). Acculturation strategies, psychological adjustment and sociocultural competence during cross-cultural transitions. International Journal of Intercultural Relations, 1, 329-343.

Ward, C., \& Kennedy, A. (1993). Psychological and socio-cultural adjustment during cross-cultural transitions: A comparison of secondary students overseas and at home. International Journal of Psychology, 28(2), 129147.

Ward, C., \& Searle, W. (1991). The impact of value discrepancies and cultural identity on psychological and socio-cultural adjustment of sojourners. International Journal of Intercultural Relations, 15, 209-225.

Wolanin, T. R. (2000). Strategies for increasing the enrollment of international student in U.S. postsecondary education. The Institute for Higher Education Policy, National Association for Foreign Student Affairs, Association for International Educators.

Yeh, C. J., \& Inose, M. (2003). International students' reported English fluency, social support satisfaction, and social connectedness as predictors of acculturative stress. Counselling Psychology Quarterly, 16, 15-28.

Zhang, N., \& Dixon, D. N. (2003). Acculturation and attitudes of Asian international students toward seeking psychological help. Journal of Multicultural Counseling and Development, 31, 205-221. 
GILBERTE BASTIEN, $\mathrm{PhD}$, is a behavioral health researcher at Morehouse School of Medicine's Satcher Health Leadership Institute. Her research and clinical interests focus on disparities in health and mental health, with an emphasis on the role of culture and its impact on accessibility, acceptability, and efficacy of mental health services for underserved populations. Email:gbastien@msm.edu

TANJA SEIFEN-ADKINS, M.S., is a graduate student in the clinical psychology doctoral program at the University of Mississippi. She received her M.S. in Psychology from the University of Bonn in Germany. Her research interests include adjustment and psychological well-being of international students, intercultural competence, and sexual satisfaction among young adults. Email: tseifen@go.olemiss.edu

LAURA R. JOHNSON, $\mathrm{PhD}$, is an associate professor of psychology at the University of Mississippi where she teaches multicultural psychology and supervises outreach programming for international and study abroad students. Dr. Johnson's research includes positive youth development, intercultural attitudes, conservation behaviors, and civic engagement, with a focus on East African youth and the internationalization of psychology.

Email: 1johnson@olemiss.edu

Manuscript submitted: December 1, 2016

Manuscript revised: July 4, 2017

Accepted for publication: January 5, 2018 